\title{
Informal park-and-ride behaviour
}

\author{
Jelena Simićevića ${ }^{a^{*}}$, Vladimir Molan ${ }^{a}$, Nada Milosavljevića \\ a University of Belgrade, Faculty of Transport and Traffic Engineering
}

\begin{tabular}{|c|c|}
\hline ARTICLE INFO & A B S TRACT \\
\hline $\begin{array}{l}\text { DOI: } 10.31075 / \text { PIS.66.01.02 } \\
\text { Professional paper }{ }^{1} \\
\text { Received: } 19.12 .2019 \\
\text { Accepted:10.01.2020 } \\
{ }^{*} \text { Corresponding author: } \\
\text { j.simicevic@sf.bg.ac.rs } \\
\text { Keywords: } \\
\text { Transport Demand Management } \\
\text { Park-and-Ride } \\
\text { Parking Management } \\
\text { Travel Behaviour }\end{array}$ & $\begin{array}{l}\text { Sustainable parking management in central urban areas typically involves } \\
\text { implementation of restrictive parking measures. Discouraged by parking } \\
\text { measures users seek for an alternative option. Some of them self-initiatively } \\
\text { found a way not to completely abandon driving: they drive and park outside the } \\
\text { central area and reach the final destination by public transport. This travel pattern } \\
\text { is known as "informal Park-and-Ride" (PnR), and should be estimated as } \\
\text { relatively positive because the critical "last mile" is travelled by public transport. } \\
\text { As PnR demand grows, policy-makers should consider its formalisation and } \\
\text { integration into the urban transport policy. This paper aims to identify informal } \\
\text { PnR users in Belgrade and to investigate their motives, requests and preferences } \\
\text { towards this option. The findings should be of importance when planning and } \\
\text { developing formal PnR sites, which can largely increase user willingness to } \\
\text { accept restrictive parking measures, i.e. to adopt more sustainable travel } \\
\text { behaviour. }\end{array}$ \\
\hline
\end{tabular}

\section{INTRODUCTION}

Almost a century of intensive car-oriented development has left many populated areas with strong uncertainties about future progress and quality of life. Cities are now searching for different programs, policies, solutions and innovations that can help sustainability efforts. As a response to sustainability requests, Transport Demand Management (TDM) is an emerging concept and a general term for policies and measures that could increase overall urban transport system efficiency and effectiveness. Essence of this are measures oriented towards modal shift from single-occupant vehicle use to more environmentally friendly and healthier modes of transport - public transport and non-motorised modes.

Parking is often seen as a key transport issue while parking problems in city centres are tackled by restrictive parking measures such as time limits and parking charges. Some users, as a response to these measures, give up parking in the central area and look for an alternative travel option. In this situation, some of them change their parking location and park outside the restricted areas, often near public transport stops.
Restrictive zoning and tariff policies in urban parking management often leads to the emergence of informal park-and-ride $(\mathrm{PnR})$ locations created on users' own initiative.

Informal $\mathrm{PnR}$ is an alternative trip choice to solely driving to the city centre and cruising and paying for parking there. One of its negative side-effects could be urban chaos and local nuisance probably in peripheral low-density zones and neighbourhood streets.

But if such behaviour does not lead to parking problem spill-over from central to peripheral areas, it should be estimated as a relatively positive, because even though it partly involves car use, the perceived critical "last mile" is travelled by public transport.

Appearance of this impromptu parking locations calls for the research of its users as the first step towards implementation of the effective formal PnR transport policy in one city, which increases user willingness to accept restrictive parking measures in city centre, i.e. to adopt more sustainable travel behaviour.

\footnotetext{
${ }^{1}$ This paper was presented at the 7th International Conference „Towards a Humane City“, 6-7th Decembar 2019. in Novi Sad, Republic of Serbia.
} 
To the best of our knowledge, the behaviour of informal $\mathrm{PnR}$ users has been rarely investigated so far. The exceptions are studies of Bullard and Christiansen (1983) and Picket and Gray (1993) which are of older date.

The aim of this paper is to identify informal PnR users and to investigate their motives, requests and preferences towards this option. The findings should be of importance when planning and developing formal $\mathrm{PnR}$ sites, which effectiveness can largely increase user willingness to accept restrictive parking measures in the city central area, i.e. to adopt more sustainable travel behaviour.

\section{PARKING MANAGEMENT IN BELGRADE}

As in other cities and towns in Serbia, most of public parking supply in central area of Belgrade is located on the streets, about $80 \%$. Since 2003 , on-street parking has been time-limited and charged. The area of parking regime and its attributes have been changed several times over time. Currently, there are four parking zones: purple, where parking is time-limited to $1 / 2$ hour and costs $100 \mathrm{RSD}$; red, where first hour of parking costs 56 RSD and following $1 / 2$ hours costs 100 RSD; yellow, where first two hours cost $48 \mathrm{RSD} / \mathrm{h}$ and the third 180 RSD; and finally, green zone, where first three hours of parking cost $41 \mathrm{RSD} / \mathrm{h}$ and the fourth hour cost 140 RSD. Regime is valid every working day from 7 am to 9 $\mathrm{pm}$ and on Saturdays from 7 am to $2 \mathrm{pm}$. Residents are entitled to purchase Parking Permit (PP) at a price of $457 \mathrm{RSD} /$ month, which enables them to park without time limitation. The same right have businesses with headquarters within the area, but at much higher prices (4.106 - 9.130 RSD/month depending on parking zone). Resident may purchase a maximum two while business three PP, out of which maximum one can be for a vehicle owned by an individual employee. There is also a possibility of reserving parking space. On-street parking state is such that almost all parking spaces are occupied during the whole day and illegal parking is common thing, which makes it difficult to find a vacant parking space.

Parking at public off-street parking lots and garages is charged non-stop, and the price varies from 60 to 120 $\mathrm{RSD} / \mathrm{h}$, with $100 \mathrm{RSD} / \mathrm{h}$ as the most common value. There is also possibility for residents and businesses to purchase different types of monthly parking tickets, but they are more expensive than the ones for on-street parking spaces. Unlike on-street parking, a vacant parking space can be easily found at any off-street parking lot and garage anytime.

Discouraged or enabled to park in the central area by its restrictive parking policy, many users decided to change their travel behaviour, typically by shifting to another transport mode.
This is especially the case for work trips, where changing the trip destination is unlikely an option. In this sense, the most acceptable solution for many of them was to travel by car in one part of the trip, then to park the car and reach the destination by public transport, i.e. to use (in)formal PnR system (Simićević et al., 2012).

In 2008 City Administration - Secretariat for Transport initiated and financed Feasibility study with preliminary design for Park and Ride system implementation (Milosavljević et al., 2008). However, to date only one site has been dedicated to this purpose. It is off-street parking lot at Vladimir Popović Street with 292 parking spaces. Tariff system at this parking lot enables its use by both PnR users and others. The former are provided with parking free of charge with a monthly ticket for public transport and previous registration at PUC "Parking Servis". The price of monthly public transport ticket depends on user category and zone. For employees it costs from 2.990 to 4.990 RSD. Other users pay parking at prices $31 \mathrm{RSD} / \mathrm{h}$ or $150 \mathrm{RSD} /$ day. Recent research (Molan and Simićević, 2019) has shown that about 500 users park their cars at this location daily, out of which about 200 are PnR users. Parking capacity is insufficient to accommodate total demand, especially from 10 am to $3 \mathrm{pm}$ when there are no vacant parking spaces. This caused parking spillover to adjacent parking lot where parking is free.

In addition to the described PnR site, it was concluded based on previous research (Milosavljević et al., 2008) and expert assessment that numerous locations are informally used for this purpose. It is they, i.e. users who use them for this purpose, that are the subject of this research.

\section{METHODOLOGY OF SURVEY}

The aim of this survey was to identify informal PnR users and to collect necessary data for assessing their behaviour, motives and requests towards this option.

Since we intended to compare the results with that obtained at the formal PnR location (Molan and Simićević, 2019), the survey methodology was compliant with the one conducted there.

The area of survey included a sample of locations previously determined to be (partly) used for informal PnR purposes. These include: Despot Stefan Boulevard (illegal on-street parking), Fire brigade (illegal on-street parking), Brankov bridge (on-street parking), Sava Centre (regulated parking near main city's motorway) and Mostar interchange (off-street parking lot). We selected locations close to the parking regime zone, as it is expected that users drive as close to the trip destination as possible. Parking at all locations is free of charge and all locations are well served by public transport, Figure 1 . 
The survey was conducted on 03., 08. and 10.10.2019. from $6 a m$ to $7 \mathrm{pm}$. Face-to-face interview of users was performed to identify informal PnR users, and to collect data on their travel and demographic characterises afterwards. This includes: trip origin and destination, parking purpose and frequency, user behaviour and preferences relating to (in)formal $\mathrm{PnR}$ option. Additionally, we collected data on driver gender and age. Above mentioned parameters proved to be important for studying informal PnR behaviour (Bullard and Christiansen, 1983; Picket and Gray, 1993).

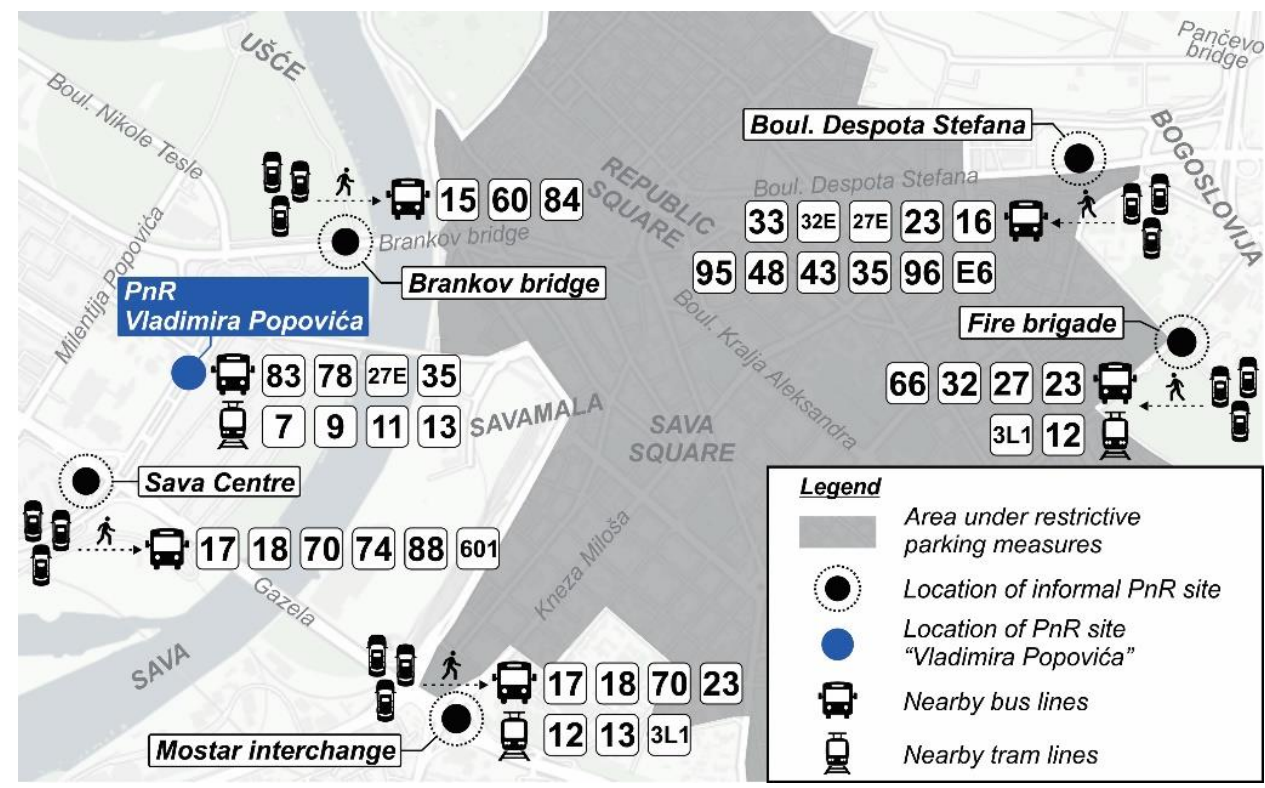

Figure 1. Area of survey

\section{RESULTS AND DISCUSSION}

Although the survey was conducted at several locations in the city (Section 3), only 26 informal PnR users were identified and interviewed. We believe the reason for relatively small sample is not that these users are rare in Belgrade, but that their paring locations are widespread throughout the city as a consequence of unregulated PnR system.

The main travel purpose of informal PnR users is "work", even though its share is smaller than at the formal PnR location ( $77 \%$ vs. $88 \%$ ). To a smaller extent there are travels with purposes of "private business" $(12 \%)$, as well as "shopping", "leisure" and "business" (with 4\% each). In line with travel purposes, an average parking duration amounts almost 8 hours and most of users travel every day (56\%) or several times a week (20\%).

From total number of respondents, $42 \%$ travels to the central area, while $58 \%$ travels to other parts of the city, suburbs and nearby towns. Average travel length by car is $6.4 \mathrm{~km}$ and by public transport $6.1 \mathrm{~km}$. Although recommendations from European countries for efficient PnR system state that the length of travel by bus from $\mathrm{PnR}$ site to the final destination should not exceed $5 \mathrm{~km}$ (Dublin Transportation Office, 2012), 28\% users travel longer distances. In addition, $23 \%$ of users have to change the line of public transport they use.
Survey results show that the number of new informal PnR users increases: $48 \%$ of respondents started to use this travel option in the last year. Before that, users travelled solely by car (52\%), solely by public transport $(43 \%)$ or used employer transport $(5 \%)$. Informal PnR did not lead to an increase in mobility, while findings from literature indicate that formal PnR system generates new trips (Meek et al., 2007). Users with travel destination in the central area gave up travelling by car more often than others ( $70 \%$ vs. $38 \%$ ). The main reason for abandoning car trips are restrictive parking measures at the travel destination: parking charge (54\%) and/or time limitation (23\%), as well as the parking state at the destination: $15 \%$ of users said that a vacant parking space was difficult to find. Only $8 \%$ of users gave up travelling by car because this way they reach their destination more quickly, even though on the way to destination $50 \%$ of users uses public transport lines with partially or completely yellow lanes and $92 \%$ do not have to change the line. On the other hand, the reasons for abandoning travel by public transport are shorter travel time (56\%) and higher comfort (44\%). It is interesting to note that these results are almost the same as those obtained at the formal site (Molan and Simićević, 2019). 
Expected impacts of PnR formalisation at the surveyed locations were also investigated. By formalisation we mean that the same tariff system as the one at formal location would be applied, i.e. that users with a monthly public transport ticket would be allowed to park free of charge. In this case, $50 \%$ of users would continue to park at the same place and to use (then formal) PnR system.

This data is quite in line with the number of users who travel every day (56\%), therefore it is assumed that they poses a monthly public transport ticket. On the other hand, the rest $50 \%$ of users would change their behaviour as such tariff system would not suit them. As a response, $23 \%$ would continue to use (informal) $\mathrm{PnR}$ system, but they would change parking location, which could lead to parking spill-over. Other users would change transport mode, mostly returning to the mode they originally used: $15 \%$ would travel by car and $12 \%$ by public transport. However, none of the users travelling to the central area would shift to a car, because they have been already discouraged by parking policy. If we observe trips to the central area only, $64 \%$ of users would not change their behaviour, $18 \%$ would change parking location and $18 \%$ would shift to public transport.

Given that the issues of equality and inclusion are necessary in the development of sustainable transport, the gender and age structure of informal PnR users was finally analysed and it was compared with the social structure of users who travel as drivers in Belgrade. The share of female informal PnR users is very high (48\%) and the similar data was obtained at the formal location, $41 \%$ of female users (Molan and Simićević, 2019). Taking into account that in total number of car trips in Belgrade female drivers represent $21 \%$ (FTTE and CEP, 2015), it can be concluded that females are more willing to change their travel behaviour and to accept alternative transport options. With regards to the age structure, the most users aged between 30 and 45 years. Their share at the formal location was $63 \%$ and in all car trips in the city $42 \%$.

\section{CONCLUSION}

Informal PnR option is used for travelling both to the central area (42\%) and elsewhere (58\%). Even though $\mathrm{PnR}$ system introduction is primarily expected to mitigate traffic congestion and parking problems in city central areas, such impact outside the central area should be also seen as positive.

Before using informal PnR option, $43 \%$ of users travelled by public transport. Shifting to driving, at least at one part of the trip, should be considered negative.
Since the reasons for modal shift from public transport to informal $\mathrm{PnR}$ are faster and easier travelling, it can be assumed that this percent could be reduced by implementing measures which increase public transport quality of service.

On average users are willing to travel by public transport $6.1 \mathrm{~km}$ and the majority of users $(77 \%)$ do not accept to change the line. This should be of importance for transport planners when selecting locations which could be used as PnR lots.

$48 \%$ of users started this travel option in the last year. Out of new users who gave up driving to the central area, everyone stated that the reason for changing travel behaviour was high parking price in the central area. Since all of them are long-term parkers and onstreet parking time limits do not suit them, it is expected that the change of behaviour was a reaction to the increase in parking price at garages which occurred in 2018, when prices increased by 10-30 RSD/h.

And generally, users who gave up travelling by car in $77 \%$ of cases did so because of restrictive parking measures at the destination. All mentioned leads to the conclusion that $\mathrm{PnR}$ system introduction should be preceded by parking regulation and control in the central area. Only $8 \%$ of users gave up travelling by car because this way they reach their destination more quickly, even though on the way to destination $50 \%$ of users uses public transport lines with partially or completely yellow lanes and $92 \%$ do not change the line.

The greater impact of restrictive measures than shorter travel times by public transport confirms literature findings that push measures are more effective in managing modal split than pull measures. This certainly does not mean that pull measures should not be applied as a support and contribution to a higher quality of service to users.

The share of users with purpose "work" is bigger at the formal $(88 \%)$ than at the informal locations $(77 \%)$. The reason could be the implemented tariff system at the formal location which suits the daily users more. This means that when defining PnR tariff system the needs of other users should be also taken into account. Otherwise, according to the survey results, negative impacts to transport system could occur.

Namely, if the same tariff system which is applied at the formal PnR lot were applied at the surveyed locations, $23 \%$ would change parking location which could lead to parking spill-over. In addition, $15 \%$ of users would shift to car use solely, which would adversely impact the realisation of targeted modal split. 


\section{REFERENCES}

[1] Bullard, D. L., Christiansen, D. L., (1983). Guidelines for Planning, designing and operating Park-and-Ride lots in Texas. Texas Transportation Institute, 1983.

[2] Dublin Transportation Office (2012). Bus based Park\&Ride - A Pilot Scheme. Dublin, 2012.

[3] Meek, S., Ison, S. G., \& Enoch, M. P. (2008). Park and Ride: Lessons from the UK experience. Transportation Research Board 87th Annual Meeting, Washington DC., Paper No. 08-0730.

[4] Milosavljević, N., et al. (2008). Feasibility study with preliminary design for "Park and Ride" system implementation [Idejni projekat sa procenom izvodljivosti uvođenja sistema "Park and Ride", 2008]. Institute of Faculty of Transport and Traffic Engineering, Belgrade. Client: City of Belgrade City Administration, Secretariat for Transport.

[5] Molan, V., Simićević, J. (2019) Park-and-ride operation characteristics in Belgrade [Karakteristike funkcionisanja sistema "Parkiraj i vozi se" - primer Beograda], Tehnika, vol. 66(3), 425-432.

[6] Picket, M. W., Gray, S. M. (1993). "Informal Park and Ride behaviour in London", Traffic and Transport Resource Centre, Transport Research Laboratory.

[7] Faculty of Transport and Traffic Engineering \& CEP. Transport Model of Belgrade 2015, Belgrade, 2015.

[8] Simićević, J., Milosavljević, N., Maletić, G., \& Kaplanović, S. (2012). Defining parking price based on users' attitudes. Transport Policy, 23, 7078. 